\title{
The Development of an Academic Engagement Intervention for Academically Dismissed Students
}

\author{
Samuel T. Beasley ${ }^{1} \cdot$ Beverly J. Vandiver $^{1} \cdot$ Ronald Dillard $^{1} \cdot$ Walter Malone $^{2} \cdot$ \\ Randy Ott ${ }^{1}$
}

Published online: 25 May 2020

(C) Springer Nature B.V. 2020

\begin{abstract}
"Reclaim the $\mathrm{W}$ " is an academic recovery program at a medium-sized midwestern university that offers undergraduates who have been academically dismissed a chance to reenroll at the institution. In this article we describe the Reclaim the $\mathrm{W}$ program and its target population of academically at-risk undergraduates. We then outline the first two phases of the process we used to develop an intervention for students in the Reclaim the W program, which we call Engage to Excel $\left(\mathrm{E}^{2}\right)$. In the first phase we collected data from focus groups with academically at-risk students and professional staff who serve these students. This qualitative data informed the creation of the $\mathrm{E}^{2}$ intervention for students in
\end{abstract}

Samuel T. Beasley earned his Ph.D. in Counseling Psychology from the University of Texas at Austin. He is an Assistant Professor of Counseling Psychology at Western Michigan University. His research focuses on academic outcomes for underrepresented college students and on men's outcomes in health service psychology doctoral programs.

Beverly J. Vandiver is a professor in the counseling psychology program in the Department of Counselor Education and Counseling Psychology at Western Michigan University. Her special interests are in scale development, cultural identities, and at-risk college students. She received her doctorate in Counseling Psychology from Ball State University.

Ronald Dillard is the Program Manager for the Alpha Program \& Reclaim the W at Western Michigan University. Ronald earned his B.A.in Secondary Education and an M.A. in Organization Communication. Currently, he is a Ph.D. candidate studying Special Education and Sociology. His research interests include the educational outcomes of students of color who have learning disabilities and students who have overcome poverty to succeed.

Walter Malone is a Clinical Fellow at the University of Kentucky Counseling Center. His special interests are Black male masculinity, racial identity development, and academic help-seeking behavior. He received his Master's degree in Educational Leadership and is currently a doctoral candidate in Counseling Psychology at Western Michigan University.

Randy Ott is the Director of the Center for Academic Success Programs at Western Michigan University. He is also a part time instructor in the School of Communications at WMU and is a public affairs officer in the U.S. Navy Reserves. His special interests are leadership development, masculinity, and first generation college students. He received his doctorate in Educational Leadership from Western Michigan University.

Samuel T. Beasley

samuel.beasley@wmich.edu

Extended author information available on the last page of the article 
the Reclaim the $\mathrm{W}$ program. In the second phase we identified key components of the quasi-experimental $\mathrm{E}^{2}$ intervention and outlined the student outcomes that will be evaluated during the intervention. Finally, we highlight research and practice implications of the $\mathrm{E}^{2}$ intervention.

Keywords Academic recovery · Student success courses · At-risk college students · Engagement . Academic intervention

Given the individual and social benefits associated with earning a postsecondary degree (Baum, Ma, \& Payea, 2010), scholars have explored ways to increase the academic success of undergraduates identified as being "at risk" for poor academic outcomes. Students who have been placed on academic probation represent one of the target populations among at-risk college students. While there are many types of students who fit into the at-risk student category (e.g., first generation college students, low income students), in using the label of at-risk students throughout this article we are explicitly focusing on students who have been placed on academic probation and those who have been academically dismissed.

Some scholars have identified the time when students are on academic probation as a "dangerous opportunity" because students and institutional stakeholders only have a small window to institute changes that will keep the student enrolled in school (Tovar \& Simon, 2006). While the specific guidelines will differ based on the institution, most postsecondary institutions offer students a limited timeframe to improve their academic performance after they have been placed on academic probation. If students fail to attain a minimally acceptable GPA, they are academically dismissed. Most institutions cut ties with students who have been academically dismissed, and typically they only allow students to return after they have taken classes at another institution and improved their GPA or after having not been enrolled for at least a semester or two and then reapplying to reenroll at the institution. A dearth of research exists on students who have been readmitted to the institution after they have been academically dismissed and on the academic recovery programs that work with them. This unique group of undergraduates thus represents a population that may require a different approach to facilitate their academic and social success.

In this article we focus on Reclaim the W (RTW), a unique academic recovery program at a midwestern university. RTW is an innovative program that invites students who have been academically dismissed to return to the University, improve their academic performance, and continue pursuing their degree. We first describe the RTW academic recovery program and the students it has served for the past five years. Next, we provide a brief literature review focused on academic interventions for at-risk students. We specifically highlight student success courses as an academic intervention given that these courses have received the most attention in the literature and that they allowed us to use an existing infrastructure to deliver our new intervention.

Considering the limited literature on academic interventions for students on probation, this article outlines the process our research team, which includes the authors of this manuscript, used to develop a theory-driven intervention for students in the RTW program. It is important to note that this article primarily focuses on the two-phase process we used before delivering the new intervention for RTW students. Later studies will focus on evaluating the outcomes of this longitudinal intervention.

The first step of this process included four focus groups to capture the experiences of multiple stakeholders, including students, professional support staff, and administrators, that informed the intervention we designed for the RTW students. The research team then 
incorporated this qualitative focus group data into the creation of an academic intervention called Engage to Excel $\left(\mathrm{E}^{2}\right)$. We decided to deliver the $\mathrm{E}^{2}$ intervention using existing student success courses in the RTW program since this course-based approach utilized existing resources at the institution. The courses provided a contained environment to address a key component of our approach which was to assess the effects and benefits of the $\mathrm{E}^{2}$ intervention on students in the RTW program. We conclude the article by highlighting the research and practice implications of the $\mathrm{E}^{2}$ intervention for academically at-risk college students.

\section{Description of Reclaim the W Program}

Established in 2014, RTW is an academic recovery program at a medium-sized, public university in the Midwest. The program was initiated under the guidance of Randy Ott, Director of the Center for Academic Success Programs. RTW was designed to target first and second-year students who were dismissed from the University in the spring semester. At this University students are placed on probation after one semester with a cumulative GPA below 2.0. If they do not obtain a cumulative GPA of 2.0 after being placed on probation for one semester, they will be academically dismissed from the University at the end of their second semester. However, if students earn a semester GPA of 2.0 or above but their cumulative GPA remains below 2.0, they are placed on extended probation and can remain enrolled in the University. Students remain on extended probation until their cumulative GPA is 2.0 or higher or they are academically dismissed from the University for earning a semester GPA below 2.0.

Students have only one path into the RTW program. At the end of each spring semester, RTW administrators receive a list of all students who were academically dismissed from the University. They invite students to apply for the RTW program based on their cumulative GPA being between 1.0 and 1.9. Students must submit a written essay detailing the issues that led to their dismissal from the University and engage in a conversation with RTW administrators as a condition of being readmitted. A team composed of RTW administrators and staff evaluates all applications for the program.

After being readmitted to the University, students are required to attend an orientation meeting that outlines the policies and performance expectations for the RTW program. All students in the RTW program reenter the University in the fall semester as a cohort. Students are required to enroll in one section of a student success course reserved just for them. Typically, there have been three to four RTW sections each fall semester with an average of 17 students in each class. Since its inception in 2014, 266 students have participated in the RTW program. Of these students, $16(6 \%)$ have completed their degree requirements and received their bachelor's degree, while another $17(6 \%)$ have applied to graduate this academic year. Of the remaining students, 93 (34\%) of RTW students are currently enrolled at the University. The final 140 students have either been academically dismissed or left the University for other reasons (e.g., finances, health issues, transfer to another institution).

Throughout the initial process of creating the $\mathrm{E}^{2}$ intervention for RTW students, our research team's goal was to document the critical elements of the intervention. This approach is consistent with calls for higher education researchers to align their practices with student development theory and research as well as to incorporate students' and practitioners' perspectives (Kuh, Kinzie, Buckley, Bridges, \& Hayek, 2006). Prior to the development of the $\mathrm{E}^{2}$ intervention in 2018, RTW instructors were given freedom to design their specific section of the RTW course. A review of syllabi from previous courses taught within the RTW program 
reveals that common topics covered in the class included time management, study strategies, test-taking skills, and learning strategies. Our team wanted to build upon the academic instruction provided to students in the RTW program over the previous four years. However, our goal was to link the new $\mathrm{E}^{2}$ intervention to established higher education theory and research as well as contextual information from the University's at-risk students.

Furthermore, as a multidisciplinary research team, we sought to capitalize on our experiences as faculty members in Counseling Psychology while collaborating with professionals and administrators in the RTW program and other entities at the University. Collaborative academic recovery interventions between academic and student affairs units deliver the best results for students, particularly when working with marginalized students and those who are at-risk for poor postsecondary outcomes (LePeau, 2015). LePeau argued that these efforts to work with atrisk students should be grounded in available research. We now offer a brief review of the literature on student success courses since our intervention used this course-based approach.

\section{Student Success Courses as an Academic Recovery Intervention}

While academic recovery interventions can be offered in multiple formats (e.g., individualized advising sessions, workshops, classes), student success courses represent one of the more popular modes of delivery for academic interventions at postsecondary institutions (Culver \& Bowman, 2020). Thus, the literature review focuses on this area. Although all students can enroll in and benefit from student success courses, they have been identified as a particularly useful intervention for at-risk students at both two-year and four-year institutions (Connolly, Flynn, Jemmott, \& Oestreicher, 2017; Kimbark, Peters, \& Richardson, 2017). Generally, student success courses are designed to provide structure and support for students, identify early concerns they may have, and connect them to appropriate on-campus resources (Hoops, Yu, Burridge, \& Wolters, 2015). Students glean information about goal setting, study habits and skills, learning styles, time management, and test-taking skills to facilitate their success in college. Addressing deficits in these areas is critical for academically vulnerable students.

Much of the available research on student success courses on college campuses has focused on first-year student success courses or seminars, and a mixed picture regarding their effectiveness has emerged (Culver \& Bowman, 2020). In their meta-analysis of 284 independent samples focused on the effectiveness of first-year seminars, Permzadian and Credé (2016) found that student success courses had a small positive effect on students' first year GPA and retention. The authors noted that, while this difference was statistically small, it has important implications for interventions within an educational context. Likewise, in their synthesis of over 1,800 empirical studies of undergraduate students' experiences, Mayhew, Rockenbach, Bowman, Seifert, and Wolniak (2016) found that first-year student success courses had a stronger effect on academic achievement and retention for academically underprepared students compared to their peers who reported stronger academic preparation for college. Mayhew et al. revealed that academic interventions are more effective if they pair these courses with tutoring or support services outside of the classroom.

Other scholars have contended that, while student success courses appear to positively affect some student outcomes, they may not exert a significant long-term effect since students may stop using the information they have learned and return to their old patterns of behavior after completing the course (Permzadian \& Credé, 2016). Additionally, these researchers have argued that few studies explore how participation in student success courses influences other 
academically relevant variables (e.g., students' engagement). Examining the effects of student success courses on outcomes other than GPA and retention, particularly for academically atrisk students, will help to assess the value of these courses.

Despite the extensive literature on student success courses (Engberg \& Mayhew, 2007), there is limited research on these courses and college students on academic probation (McGrath \& Burd, 2012). While sparse, extant studies present limited but promising results. In their quasi-experimental study with students on probation enrolled in a student success program at a large, public university, McGrath and Burd (2012) found that students who participated in the student success course had higher rates of getting off academic probation and evidenced higher persistence and graduation rates compared to their peers who had not taken the course. Lizzio and Wilson (2013) reported that providing structured feedback to firstyear students who had failed coursework contributed to their achieving both higher short-term success (i.e., improved grades on in-class assignments) and long-term success (i.e., passing the course). Faculty members who provide structured feedback to academically at-risk students can help them identify specific strategies to improve their performance.

Other research shows that student success courses at 2-year institutions were more effective than those offered at 4-year institutions because they target the higher number of academically underprepared students at these institutions who most need academic assistance (Permzadian \& Credé, 2016). These studies indicate that courses for students on probation may be effective but that more work is needed to identify the critical elements of these courses that assist at-risk learners.

While studies on using student success courses to deliver academic recovery interventions for students on probation is sparse, even less work is available that explores academic recovery interventions for academically dismissed students after they have been readmitted to the institution. Most institutions cut ties with students after they have experienced academic problems for at least two semesters and have not adequately improved their academic performance. As such, readmitted students represent a unique population that has not received attention within the extant literature even though they may require a different approach to facilitate their success. This study outlines our effort to address this gap in the literature.

\section{The Study}

\section{Purpose}

This brief literature review highlighted the limited information on student success courses for students on probation (Hensley, Wolters, Won, \& Brady, 2018; Lizzio \& Wilson, 2013; McGrath \& Burd, 2012) as well as the paucity of studies on students who have been readmitted to their institutions after being academically dismissed. To address this gap in the literature, we outline the first two phases of the process our research team used to create an academic intervention for students in the RTW program.

After receiving IRB approval, our primary goal for the first phase was to glean more insights about the experiences and needs of academically at-risk students who attend the University and identify gaps highlighted by students and professional staff who are involved with academic support programs for at-risk students. This approach was designed to incorporate valuable contextual information from the perspectives of multiple stakeholders (i.e., at-risk students enrolled in academic support programs at the institution, professional support staff, and administrators) about their experiences at the University. It also allowed us to build 
content into the intervention that would address the unique challenges students in the RTW program faced while pursuing their undergraduate degrees.

\section{Participants}

Prior to collecting focus group data, the study had received approval from the institution's Human Subjects Review Board. Participants for this study were derived from three key groups of stakeholders (at-risk students attending the University, student support professionals, and administrators who served these students). Students who could provide insights about their experiences participating in academic recovery or student success programs were recruited from three academic support programs at the institution (Collier, Parnther, Fitzpatrick, Brehm, \& Beach, 2019). These participants for the focus groups were recruited from these programs since their demographic profile (i.e., first generation status, SES background, race/ethnicity, level of academic preparation) mirrored the backgrounds of students who enter the RTW program.

We invited 120 student participants from these three programs to participate in the focus groups, and 26 students responded for a $21 \%$ response rate. The size of the focus groups ranged from 4 to 13 participants. Fifteen persons identified as women, and 10 identified as men, with one individual not reporting this information. In terms of racial make-up, the sample included 16 African American/Blacks, 3 Afro-Latinos, 2 Latinx, 2 White, 2 multi/biracial, and 1 Middle Eastern student. The second author facilitated the student focus groups, which lasted an average of $78 \mathrm{~min}$.

We also recruited student support professionals at the University and administrators for the RTW program to participate in a separate focus group, which included four women and three men. We had invited all 15 professionals who served students in four academic support programs to participate, which resulted in a $47 \%$ response rate. These individuals reported having a minimum of two years of experience in providing services to students at the institution. The first author facilitated this focus group, which lasted $84 \mathrm{~min}$.

\section{Procedure}

We recruited participants for the student focus groups by sending a recruitment email to administrators from their respective academic support programs. These administrators then forwarded the recruitment email to all of their students. We recruited the administrators and professional staff by directly inviting them to participate in the study via email. We offered separate time slots for the three student focus groups and the professional staff focus group which allowed participants to select an interview time that fit their schedule. We developed two semi-structured interview protocols for the focus groups. The student focus group protocol contained eight questions, and the support protocol consisted of seven questions. Both protocols were developed using available literature on academic support programs and supporting at-risk college students.

\section{Data Analysis}

The first author used thematic analysis to analyze the focus group data (Braun \& Clarke, 2006). Using the process outlined by Braun and Clarke (2006), he analyzed the data by grouping similar ideas or meaning units to develop preliminary themes. After these initial codes were developed, he recoded the data to eliminate redundant themes. In a follow-up round of coding, the first author reanalyzed the data to ensure the final thematic structure 
accurately reflected the data from the focus groups (Braun \& Clarke, 2006). Two doctoral students then reviewed the data to ensure clarity and thoroughness of the thematic structure. Following this review process, the first author made minor changes based on their feedback prior to writing up the data.

\section{Findings}

\section{Student Focus Groups}

Students' perceptions of their inadequate preparation for college represented the first theme in the data. Twenty-two of the 26 students reported that they did not feel prepared for college. One participant stated that he realized he was not ready for college on "the first day of orientation." The students acknowledged that they struggled to adjust to the academic demands of college compared to the academic standards of their high schools. For example, one participant explained that she had been informed by teachers in her high school that she was being prepared for the expectations of college professors; but she later realized that their preparation had set the bar too low: "They would claim this is a college-going culture, and that was just them saying 'stay off of your phone' or 'come to class on time'." Students argued that the focus on behavior management at their high school had failed to provide them with the requisite knowledge and skills needed for postsecondary work, which made the transition to doing college-level classes more challenging and partially explained their early academic struggles on campus. Given that students in the RTW program had been academically dismissed, these initial academic struggles clearly persisted across their time at the University.

In light of this perceived and apparent poor academic preparation, students in the focus groups reported that access and use of university resources was important for their academic success. These responses accounted for the second theme from the student focus groups. One student stated:

I've been to the [Masked Name], and I love it because I have a peer coach. I'll meet with her twice a week. I would not have passed math first semester if it wasn't for her. She's my same peer mentor this semester. It's that one-on-one; I need that personally. I'm selfmotivated, and I'll do it myself, but just that extra pushing, that extra help really helps me.

Students explained that they had been directed to use various campus support services (e.g., Writing Center), but they noted that they did not consistently access these resources. Sometimes when students did engage with these support services, they acknowledged that the services they received were not as helpful for them. One participant reported that "the tutors, they try their best. Sometimes they know more than what they can express in layman's terms." Similar to the tutors, faculty members were perceived as a potential on-campus resource, but students were not always able to receive the help they needed from them. One participant explained, "It's a mixed response. I have some teachers who are willing to help, but then I have some of the other teachers where [they say], 'Oh yeah, you can figure it out." When academically at-risk students like those in the RTW program encounter faculty or staff members who are perceived as not being helpful to them when they seek academic support, they may be more likely to get discouraged and not actively work to locate alternative sources of support. Considering that students found on-campus resources were generally helpful to 
them if they used them consistently, encouraging students to persist in using these resources may be one strategy that could be stressed for students in the RTW program.

The impact of social identities on academic experiences represented the third theme identified from the student focus groups. In all three focus groups, participants discussed how their personal identities, including their race/ethnicity, gender, first-generation status, and age, shaped their experiences on campus. One participant noted that racial group membership served as a motivational factor:

I'm Hispanic and Black, and the way it's influenced me so far in college is just staying focused on school because both of my parents didn't have the opportunity. And most of my Hispanic family didn't go to college or finish high school, so that's really kind of motivating me to focus on school.

Other students shared how their social identities affected their interactions with faculty and peers. For example, students detailed how their status as visible minorities at the predominately White institution influenced their peer relationships and their sense of belonging in the classroom and on campus. For example, one student noticed that his White peers "feel more comfortable around each other. They talk to each other about assignments and whatnot. I have to literally step outside of myself and deal with all these extra barriers and boundaries that they don't have to deal with."

Other students reported that the limited diversity on campus contributed to negative experiences with peers, which they connected to several of their identities. One Black woman's story exemplified how race and gender influenced her in-class experiences:

So I was in class a few weeks ago, and I was having a discussion with two Caucasian males in class. And they were [saying], 'I'm going to be a corporate, corporate White guy, CEO, stuff like this and, you know, you're going to be the woman being the assistant.' And when he said that you're going to be the assistant, so basically not making me eligible to be the CEO. And why is that? Because I'm a woman? Because I'm Black? Because we're in the same class, getting the same education, but why can't I?

These stories highlight ways in which students' social identities can serve to motivate them, but these same identities can also expose them to additional stressors that affect their integration and satisfaction at the University. Taken together, students in the focus groups felt that they lacked the necessary academic skills when they entered college and had to seek oncampus resources to deal with gaps in their academic preparation. Accessing these resources did not automatically ensure their success given the differences in the quality of the resources utilized, and students have to be able to persist in their efforts to find helpful resources. Additionally, students recognized that their different social identities affected their experiences on campus. While their identities were not explicitly linked to the academic problems they reported, these students noted that they shaped their on-campus interactions. These experiences add another barrier that academically at-risk students in the RTW program must navigate to achieve academic success.

\section{Professional Stakeholders Focus Group}

Professional support staff identified three themes that underscored their experiences working with academically at-risk students at the institution. They recognized students' inadequate 
preparation for college, which represented the first theme. They reported that students were often not ready for the expectations of higher education and struggled to manage the freedom and responsibilities of college life. One staff member explained as follows:

I hear a lot of 'Oh, I didn't have to study in high school, and now I have to study. I don't know how to study. I don't know how to read a textbook, understand it. I don't know what I'm reading.' So I see a lot of that.

One administrator concurred with their colleagues' assessment of students' inadequate preparation for college and their early academic struggles at the University:

You'll have a kid that might have a 4.0 who never studied, and then they come here. And since they're not in front of their teachers as much, they're not in class as much, there's so much down time. You pretty much come to campus, do your classes, and then you can go home and do whatever.

The participants noted that students' lack of prior preparation contributed to their failure to structure their downtime to minimize procrastination and distractions that negatively affected their performance. Students would consequently get stuck in a cycle of academic procrastination and failure that eventually led to their dismissal from the university.

While student support staff and administrators acknowledged that academic problems, such as poor academic preparation, were contributors to students' subpar grades, they noted that focusing exclusively on academics failed to explain students' struggles. Professional staff reported in the second theme that broader issues affect students' performance. They noted that students were often dealing with multiple issues that directly and indirectly influenced their academic performance. One administrator reported that some students' efforts to balance their family's expectations contributed to their academic struggles:

[Parents] pushing students into majors that they may not be passionate about because it makes more money. I see a lot of that from our students so they get stuck in this cycle of doing poorly and struggling, and that adds to their stress.

They also discussed how family issues, mental and physical health problems, and financial concerns represented other non-academic concerns that affected at-risk students they served. One staff member reported that their students were juggling multiple responsibilities that inhibited their engagement on campus:

They are the responsible one in their family, so they have a hard time leaving that behind and being the college student on-campus because they may still be driving back and forth to take brothers and sisters to school in the morning or whatever they have to do. I think that's hard for them too.

In the final theme, professionals focused on the impact of students' social identities on their engagement. They highlighted how students' social identities affected their perceptions of cultural fit and sense of belonging at the University. One staff member explained that students struggled to develop a sense of belonging during their transition to college.

One of my students described coming here was a culture shock for her. There wasn't [sic] enough [Black] people. She's never been in a place where she was literally the minority and being in the classroom with 200 and something people and you're the only African American person sitting in there. That scared her, and she felt like she didn't 
belong here. She felt like a lot of the clubs and organizations that were geared for her were very few, and she just felt like it wasn't the place for her to be, and she was thinking about going to an HBCU for those reasons.

Professional staff noted that they worked to get students more engaged by helping them to navigate experiences of being either first generation, low income, or a student of color in higher education by addressing students' "exposure gaps." One staff member commented that many students “don't get to know people in positions of power on campus. They don't go out. They stay in their bubbles and don't branch out to expand their networks beyond their friends." These professionals noted that students' pre-existing beliefs may lead to lower engagement on campus. One administrator reported that he worked with students to address their worries:

[Some underrepresented students deal with the] fear of doing something different from what you've already done or what you've been exposed to, especially when it comes to Study Abroad or going to an organization that you wouldn't have thought to go to because of the benefits that it can add to your skillset.

By addressing knowledge gaps created by students' first generation or low income status as well as their experiences as racial minorities at the institution, these professionals worked to build relationships with students and help them connect with culturally relevant and supportive resources on campus. These bridging efforts can enhance students' academic and social engagement on campus, which can contribute to their satisfaction and academic performance in school.

\section{Discussion}

The purpose of the first phase of this project, the focus groups, was to catalogue the experiences of academically at-risk students and the professional stakeholders who work directly with them as we created an intervention for students in the RTW program. Prior research has encouraged researchers to include the voices of multiple stakeholders when crafting student-centered interventions (LePeau, 2015). The inclusion of data from the four focus groups ensured that our intervention incorporated contextual factors that may affect students in the RTW program. By gathering the perspectives of both at-risk students as well as the professionals tasked with facilitating their academic success prior to creating the intervention, we were able to tailor the intervention specifically to the at-risk students in the RTW program. Given that both groups identified similar factors contributing to students' academic challenges, we were able to hone in on these areas and increase buy-in from students and professional stakeholders. Other programs may benefit from taking a similar approach as they create new academic interventions. This early buy-in can help to generate a shared problem statement and lead to a more cohesive plan that does not rely exclusively on certain stakeholders' perspectives of the problem.

Stories from the four focus groups revealed that students felt unprepared for the rigors of college and needed assistance developing the academic skills (e.g., time management, effective study strategies) that would improve their academic performance. While all students must develop these vital skills, our findings indicate that students like those in the RTW program need additional support. Compared to other at-risk students on campus, students in the RTW program are unique since they are being readmitted to the institution after they failed to make 
adequate academic progress for multiple semesters on campus and were academically dismissed. The stressors associated with these chronic academic struggles not only affect students' academic self-concept and motivation; they can also affect them psychologically and emotionally. Our findings suggest that this subset of students requires supplemental academic skills development and support beyond what is typically offered during most students' first semester or year on campus. This support entails a more hands-on and holistic approach that may less necessary for other at-risk students at the institution after this timeframe.

In the focus groups both students and professional staff agreed that students were aware of resources on campus but did not always engage with them to deal with gaps in their academic competence. Students' inconsistent use of services is exacerbated by their inadequate academic preparation entering college. Given that some of students did not always have the perception that on-campus resources (i.e., faculty or tutoring services) met their needs or expectations, some atrisk students at the University may be discouraged after seeking out the resources identified by professional staff. This sense of disillusionment with the quality of academic services may be exacerbated for at-risk students like those in the RTW program due to procrastination and the internalized stigma associated with having multiple semesters of academic failure. This stigma likely contributes to feelings of hopelessness and learned helplessness as well as limited oncampus engagement that must be addressed in subsequent interventions.

Psychological barriers to engagement, such as help-seeking stigma and learned helplessness, may also account for the differing explanations that students and professional stakeholders provided for at-risk students' lack of engagement at the University. Both groups spoke to the value of engagement with multiple parties on campus to learn new academic skills, address knowledge and exposure gaps, and achieve optimal results. However, students who did not engage on campus may focus on internal traits to explain their behavior. Professional staff, on the other hand, attributed students' lack of engagement to non-academic factors and recognized that these factors called for a holistic perspective to account for students' academic struggles. Thus, interventions for academically dismissed students must not only focus on academic skills deficits; they must also address students' psychological, emotional, and cognitive beliefs given that these factors may affect their academic performance, particularly for students who have experienced sustained academic problems at the university.

Furthermore, our findings also revealed that some students, particularly students of color, encounter unique identity-related challenges on campus. Both students and professionals detailed the impact of the University's cultural climate on students and emphasized the need to take this context into account when working to engage this at-risk population. Negative experiences on campus can have an adverse effect on these students as they are navigating the everyday challenges associated with being a college student (Quaye \& Harper, 2015). Our findings suggest the need for a multidimensional understanding since students' lack of academic preparation, social identities, and non-academic concerns may contribute to their ability to get off academic probation and progress in their academic programs.

\section{Conceptual Framework of the Engage to Excel Intervention}

Combining the insights we gleaned from the focus groups with students as well as professional staff in the first phase of this project, we transitioned to the second phase of the research process. During this phase we created an interdisciplinary and theory-driven intervention for students in the RTW program, which we labeled Engage to Excel $\left(\mathrm{E}^{2}\right)$. The $\mathrm{E}^{2}$ intervention for 
RTW students has two distinctive and innovative features. These two features are its focus on the integration and application of a targeted model of student engagement alongside a group counseling approach in the classroom, which we now explain.

\section{Student Engagement}

The foundational component of the $\mathrm{E}^{2}$ intervention for RTW students is its explicit emphasis on student engagement (Astin, 1999; Tinto, 2001). Higher education research has clearly documented that students who are more engaged on campus have more positive educational outcomes than do their less engaged peers (Kuh et al., 2006; Quaye \& Harper, 2015). Although prior research acknowledges the relationship between student engagement and positive educational outcomes (Kuh et al., 2006), less is known about specific interventions that are designed to increase at-risk students' engagement. Based on our focus group findings, we recognized that students in the RTW program had already learned some basic academic skills in their first year seminar courses; but they needed more time to apply and practice these skills due to the gaps in their academic preparation. Thus, the primary objective in the $\mathrm{E}^{2}$ intervention was to help students increase their level of engagement across multiple domains and evaluate its effect on their subsequent academic performance.

The $\mathrm{E}^{2}$ intervention introduces students to the $\mathrm{ABCs}$ (i.e., affective, behavioral, cognitive, and social) of engagement and assesses them on their application of these principles (Parsons, Nuland, \& Parsons, 2014). Students are taught the ABCS of engagement during the first part of the intervention. These four areas of engagement are then explicitly integrated and assessed through in-class and outof-class activities throughout the rest of the intervention. Additional information about the ABCS of engagement that we are in the process of evaluating within the $\mathrm{E}^{2}$ intervention is outlined below.

\section{Affective Engagement}

Postsecondary scholars acknowledge that engagement is multidimensional and must incorporate students' affect or feelings about school when evaluating their engagement (Parsons et al., 2014). Affective engagement incorporates students' positive (e.g., enjoyment or interest) and negative (e.g., anxiety or discouragement) emotional responses to their academic experiences (Wilson et al., 2015). Affective engagement includes students' sense of belonging within the classroom or at college. In the $\mathrm{E}^{2}$ intervention, affective engagement is being evaluated using measures of affect, students' selfreports of affective engagement as well as multiple in-class evaluations by trained observers.

\section{Behavioral Engagement}

Behavioral engagement denotes actions and practices that students use to stay involved in learning and academic tasks (Wang \& Eccles, 2013). It can involve effort and participation in academic activities (Wilson et al., 2015). Drawing on the work of behavioral psychologists, the focus of behavioral engagement within the $\mathrm{E}^{2}$ intervention is ensuring that students engage in specific behaviors on a daily and weekly basis. Prior research has shown the value of behavioral activation and mastery activities for changing unhelpful behaviors, particularly when combined with other types of engagement (Kanter, Busch, \& Rusch, 2009). Examples of behavioral engagement within the $\mathrm{E}^{2}$ intervention include but are not limited to the following: (a) completion of weekly behavioral tracking sheets, (b) attending structured study times (alone or with others), and (c) use of oncampus and off-campus resources (e.g., University's Writing Center, meetings with faculty). 


\section{Cognitive Engagement}

Cognitive engagement involves students' use of metacognitive and self-regulated strategies (Parsons et al., 2014). It also addresses the psychological and attitudinal factors that can contribute to or hinder students' academic performance based on their cognition or thoughts. Cognitive engagement can incorporate evaluation of students' internalized self-beliefs that subsequently contribute to their outcomes (Kanter et al., 2009) as well as positive and negative patterns of cognitive engagement. Positive cognitive engagement involves cognitive strategies that students use to overcome barriers to their academic success, including academic selfconcept, hope, and resilience. Negative cognitive engagement involves overreliance on cognitions that fuel self-handicapping, academic avoidance, procrastination, and imposter feelings. Both of these forms of cognitive engagement are being assessed in the intervention.

\section{Social Engagement}

Social engagement refers to students' involvement with their peers in both in-class and out-ofclass activities (Quaye \& Harper, 2015). These out-of-class activities can be both formal and informal. Formal out-of-class activities include involvement with student organizations, volunteer opportunities, and extracurricular activities. Informal out-of-class activities involve any activities that are not formally organized by the institution but that allow students to engage with each other (Quaye \& Harper, 2015). Social engagement incorporates student-faculty interactions, such as visiting professors in their offices and talking with professors before or after class. Also, we assess the impact of cultural variables on social climate and engagement for diverse students in the intervention (Quaye \& Harper, 2015). Social engagement is being evaluated using weekly behavioral trackers as well as using measures on social engagement attitudes.

\section{Group Counseling Format in Classroom Setting}

The second innovative feature of the $\mathrm{E}^{2}$ intervention is our team's use of a classroom-based group counseling approach. While the $\mathrm{E}^{2}$ intervention will be offered in the classroom like other student success courses, it differs from these courses since it integrates aspects more commonly found in group counseling offered by psychologists in the university counseling center. This group counseling approach in the classroom combines the traditional focus within student success courses on developing academic skills with some of the interventions psychologists use to address holistically more of the broader concerns faced by academically atrisk students as highlighted in the focus groups.

It is important to note that student affairs professionals often offer this type of support to students individually. However, our team believed that we could use the classroom setting to deliver a similar intervention in a group setting using our team's expertise as counseling psychologists. While student affairs professionals and some faculty receive limited training to address the social and emotional aspects of students' academic experiences, psychologists are equipped to delve deeper into these issues and can use the power of the group setting to facilitate this process.

The group counseling approach is embedded into the structure and content of the $\mathrm{E}^{2}$ intervention for RTW students. For example, similar to group counseling process, students "check in" at the beginning of each class period. During their check-ins, they share about successes and challenges from the previous week or for the upcoming week. The instructor and classmates can ask clarifying questions and give encouraging words. Students can also 
request additional class time to discuss and receive feedback about any pressing concerns affecting their academic performance. This open sharing at the start of every class period helps to normalize the act of seeking help and allows students to recognize their common academic challenges, which can reduce the stigma for doing so. It also allows students to support each other's victories from the previous week and hold each other accountable if they are not reaching their established engagement goals. Additionally, students can learn to recognize maladaptive academic behaviors in themselves and others and hear about resources that helped their peers address their academic problems.

This group counseling approach differs from available academic recovery interventions since it draws on the power of the group to normalize seeking help and to challenge psychological barriers to engagement. Using the classroom as an academic group counseling session, the instructor of the course uses their psychological training to begin helping students to address the multifaceted problems they are facing without having them visit the University's counseling center immediately. Students' non-academic concerns, such as mental health, family stressors, financial barriers, and adjustment concerns, can be discussed in the checkins as well as in the assigned readings for the course (Beattie, Laliberté, Michaud-Leclerc, \& Oreopoulos, 2019). This counseling group approach reduces the separation of students' academic challenges from the broader issues that they face and allows students' problems to be diagnosed and treated earlier. Using the group counseling format in the classroom, students continue to receive traditional instruction on academic skills, such as time management, procrastination, and study skills, given that our focus groups revealed that these deficits were a concern for at-risk students at our University. However, it also allows this subset of academically at-risk students to receive assistance in identifying and removing barriers to their full academic and social engagement on campus.

\section{Implementation and Assessment of the Engage to Excel Intervention}

We delivered the $\mathrm{E}^{2}$ intervention using the existing course sections within the RTW program. This intervention utilizes a mixed methods, pre/post-test experimental design that is occurring in two phases and started with the fall 2018 cohort of students in the RTW program. In fall 2018 students were randomly assigned to one of the three student success course sections reserved for RTW students. We gathered baseline data from all students in the RTW program at the start of the fall semester. Our research team was assigned one section of the RTW students, and the first author delivered the experimental $\mathrm{E}^{2}$ intervention throughout the fall 2018 semester to this one section.

Using a longitudinal design, we have been gathering data on the effects of the $\mathrm{E}^{2}$ intervention over the past two academic years to document the critical elements of this approach and to assess its effectiveness empirically. All students in the fall 2018 cohort were re-assessed in spring 2019, and additional data will be collected from this first cohort in spring $2020 .{ }^{1}$ In fall 2019, one section of RTW students received the $\mathrm{E}^{2}$ intervention. This second cohort of RTW students from fall 2019 will be tracked and assessed over a 2-year time span to gather enough data in order to evaluate the statistical significance of the $\mathrm{E}^{2}$ intervention for

\footnotetext{
${ }^{1}$ We were scheduled to collect the second round of data at the end of the spring 2020. Due to the disruptions caused by COVID-19, our data collection process will be delayed; but we are developing a process to gather this data.
} 
RTW students. We will assess outcomes including whether the $\mathrm{E}^{2}$ intervention helps students' increase their GPA, transition off academic probation, and achieve junior level status at the University. Additionally, we will analyze the engagement patterns of students in the fall 2018 and 2019 sections of the $\mathrm{E}^{2}$ classes of RTW students with their peers in the two other fall 2018 and 2019 sections of students in the RTW program. Students in the other two sections of the RTW classes will serve as a treatment-as-usual control group. We have collected background information for all students in the fall 2018 and 2019 cohorts so that their academic profiles prior to their entry into the University can be compared. Finally, we will supplement these quantitative data with qualitative interviews from students in the fall 2018 and fall 2019 cohorts.

It is important to acknowledge the challenges of evaluating the $\mathrm{E}^{2}$ intervention. The use of control versus treatment groups represents one ethical concern. However, considering that students in the control group will continue to receive services that were previously available via the RTW program, they will not be harmed by remaining in the control group. Additionally, the use of a control group allows us to account for the volunteer effect for the students who elect to apply for the RTW program. The control group allows us to assess whether the intervention provides benefits above and beyond what is already offered to students in the academic recovery program.

\section{Implications of the Engage to Excel Intervention}

Embedded within the RTW program, we believe that the $\mathrm{E}^{2}$ intervention represents an innovative academic recovery approach. The effort to operationalize engagement principles within a classroom setting represents one strategy for translating theory and research on student engagement into practice. Additionally, another strength of the $\mathrm{E}^{2}$ intervention is the use of a group counseling approach in the classroom, which integrates multi-dimensional factors for improving the academic outcomes of at-risk students. Its integration of the strengths of counseling psychologists, student affairs personnel, and other higher education professionals allows it to more flexibly address the problems academically dismissed students encounter. This approach can shift how academic recovery courses are designed and delivered. While it is clear that a focus on basic academic skills needs to remain a focus, moving from a didactic approach to one that centers upon student engagement may prove more efficacious for students who are academically struggling.

Additionally, encouraging faculty and staff who teach these courses to integrate a focus on the personal aspects of students' experiences may help to destigmatize these issues and highlight resources that students can use. Future researchers and practitioners may seek to replicate and extend the principles embedded in the $\mathrm{E}^{2}$ intervention as well as to explore other interventions that center student engagement. Researchers can continue exploring proactive engagement interventions with at-risk students, with a particular emphasis on students who are placed on academic probation and at-risk of academic dismissal. For example, it may be useful to evaluate the benefits of introducing an engagement intervention for students placed on academic probation after the first semester.

Given that engagement is shaped by contextual factors, it is important to gather quantitative and qualitative data that capture how students' social experiences and the social climate affects their engagement (Quaye \& Harper, 2015). While the research is clear that engagement matters for students' success, more work can be done to identify barriers to engagement for marginalized populations and incorporate practices that allow all students to receive the benefits of academic and social engagement. 


\section{Conclusion}

Although we believe that the RTW program is an innovative program for academically at-risk college students, the creation of a targeted engagement intervention represents the next step in serving these students. The $\mathrm{E}^{2}$ intervention introduces practitioners and researchers to one approach for setting up and assessing a student engagement intervention. Postsecondary institutions must strive to create learning environments where the most academically vulnerable students are able to engage and fully realize their potential. This effort can be achieved by placing more emphasis on interdisciplinary partnerships that combine the expertise of all institutional stakeholders to the benefit of these students.

\section{References}

Astin, A. W. (1999). Student involvement: A developmental theory for higher education. Journal of College Student Development, 40, 518-529.

Baum, S., Ma, J., \& Payea, K. (2010). Education pays 2010: The benefits of higher education for individuals and society (trends in higher education series). New York, NY: College Board Advocacy \& Policy Center.

Beattie, G., Laliberté, J. W., Michaud-Leclerc, C., \& Oreopoulos, P. (2019). What sets college thrivers and divers apart? A contrast in study habits, attitudes, and mental health. Economics Letters, 178, 50-53. https://oi. org/10.1016/j.econlet.2018.12.026

Braun, V., \& Clarke, V. (2006). Using thematic analysis in psychology. Qualitative Research in Psychology, 3, 77-101. https://doi.org/10.1191/1478088706QP063OA

Collier, D., Parnther, C., Fitzpatrick, D., Brehm, C., \& Beach, A. (2019). Helping students keep the promise: Exploring how Kalamazoo promise scholars' basic needs, motivation, and engagement correlate to performance and persistence in a 4-year institution. Innovative Higher Education, 44, 333-350. https://doi. org/10.1007/s10755-019-9468-0

Connolly, S., Flynn, E. E., Jemmott, J., \& Oestreicher, E. (2017). First year experience for at risk college students. College Student Journal, 51, 1-6.

Culver, K. C., \& Bowman, N. A. (2020). Is what glitters really gold? A quasi-experimental study of first-year seminars and college student success. Research in Higher Education, 61, 167-196. https://doi.org/10.1007 /s11162-019-09558-8

Engberg, M. E., \& Mayhew, M. J. (2007). The influence of first-year "success" courses on student learning and democratic outcomes. Journal of College Student Development, 48, 241-258. https://doi.org/10.1353 /csd.2007.0023

Hensley, L. C., Wolters, C. A., Won, S., \& Brady, A. C. (2018). Academic probation, time management, and time use in a college success course. Journal of College Reading and Learning, 48, 105-123. https://doi. org/10.1080/10790195.2017.1411214

Hoops, L. D., Yu, S. L., Burridge, A. B., \& Wolters, C. A. (2015). Impact of a student success course on undergraduate academic outcomes. Journal of College Reading and Learning, 45, 123-146. https://doi. org/10.1080/10790195.2015.1032041

Kanter, J. W., Busch, A. M., \& Rusch, L. C. (2009). Behavioral activation: Distinctive features. New York, NY: Routledge.

Kimbark, K., Peters, M. L., \& Richardson, T. (2017). Effectiveness of the student success course on persistence, retention, academic achievement, and student engagement. Community College Journal of Research and Practice, 41, 124-138.

Kuh, G. D., Kinzie, J. L., Buckley, J. A., Bridges, B. K., \& Hayek, J. C. (2006). What matters to student success: A review of the literature (Vol. 8). Washington, DC: National Postsecondary Education Cooperative.

LePeau, L. (2015). A grounded theory of academic affairs and student affairs partnerships for diversity and inclusion aims. The Review of Higher Education, 39, 97-122. https://doi.org/10.1353/rhe.2015.0044

Lizzio, A., \& Wilson, K. (2013). Early intervention to support the academic recovery of first-year students at risk of non-continuation. Innovations in Education and Teaching International, 50, 109-120. https://oi. org/10.1080/14703297.2012.760867

Mayhew, M. J., Rockenbach, A. N., Bowman, N. A., Seifert, T. A., \& Wolniak, G. C. (2016). How college affects students: 21st century evidence that higher education works (Vol. 3). San Francisco, CA: Wiley. 
McGrath, S. M., \& Burd, G. D. (2012). A success course for freshmen on academic probation: Persistence and graduation outcomes. NACADA Journal, 32, 43-52. https://doi.org/10.12930/0271-9517-32.1.43

Parsons, S. A., Nuland, L. R., \& Parsons, A. W. (2014). The ABCs of student engagement. Phi Delta Kappan, 95, 23-27. https://doi.org/10.1177/003172171409500806

Permzadian, V., \& Credé, M. (2016). Do first-year seminars improve college grades and retention? A quantitative review of their overall effectiveness and an examination of moderators of effectiveness. Review of Educational Research, 86, 277-316. https://doi.org/10.3102/0034654315584955

Quaye, S. J., \& Harper, S. R. (Eds.). (2015). Student engagement in higher education: Theoretical perspectives and practical approaches for diverse populations. New York, NY: Routledge.

Tinto, V. (2001). Rethinking the first year of college. Syracuse, NY: Syracuse University.

Tovar, E., \& Simon, M. A. (2006). Academic probation as a dangerous opportunity: Factors influencing diverse college students' success. Community College Journal of Research and Practice, 30, 547-564. https://doi. org/10.1080/10668920500208237

Wang, M.-T., \& Eccles, J. S. (2013). School context, achievement motivation, and academic engagement: A longitudinal study of school engagement using a multidimensional perspective. Learning and Instruction, 28, 12-23. https://doi.org/10.1016/j.learninstruc.2013.04.002

Wilson, D., Jones, D., Bocell, F., Crawford, J., Kim, M. J., Veilleux, N., et al. (2015). Belonging and academic engagement among undergraduate STEM students: A multi-institutional study. Research in Higher Education, 56, 750-776. https://doi.org/10.1007/s11162-015-9367-x

Publisher's Note Springer Nature remains neutral with regard to jurisdictional claims in published maps and institutional affiliations.

\section{Affiliations}

\section{Samuel T. Beasley ${ }^{1} \cdot$ Beverly J. Vandiver $^{1} \cdot$ Ronald Dillard $^{1} \cdot$ Walter Malone $^{2} \cdot$ Randy Ott ${ }^{1}$}

Beverly J. Vandiver

bvndvr@gmail.com

Ronald Dillard

Ronald.d.dillard@wmich.edu

Walter Malone

w0malone@wmich.edu

Randy Ott

Randy.Ott@wmich.edu

1 Western Michigan University, Kalamazoo, MI 49008-5226, USA

2 University of Kentucky, Lexington, KY, USA 